\title{
Nefritis del shunt
}

\author{
Viviana Parra $\mathrm{I}^{1}$, Patricia Medina $\mathrm{A}^{2}$, Sandra Valderrama $\mathrm{B}^{3}$, Sandra Gualtero $\mathrm{T}^{3}$ \\ ${ }^{1}$ Universidad de La Sabana
2 Médica Interna, Hospital Militar Central
${ }^{3}$ Fundación Clínica Shaio
}

\section{Resumen}

La nefritis por shunt es una complicación poco frecuente que se asocia al uso de derivaciones ventriculoatriales y su infección crónica. Las bacterias que la producen, por lo general, son de baja virulencia, pero producen infección prolongada y persistente permitiendo así la producción de inmunocomplejos que se depositan a nivel renal. Queremos describir un caso de una adolescente con hidrocefalia posterior a un evento de meningitis, con uso de derivación ventrículoatrial quien ingresa con un cuadro de fiebre y escalofrío de larga evolución, en la cual se documentó infección del dispositivo y nefritis por shunt.

Palabras clave: Nefritis por shunt, inmunocomplejos, endocarditis.

\section{Shunt nephritis}

\section{Summary}

Shunt nephritis is a rare complication associated with the use of atrialventricular shunts and their chronic infection. The microorganisms that cause the infection are generally of low virulence, but they can produce long term infections that permit the production of immune complex that deposit in the kidneys leading to nephritis. Because of this we want to describe the case of an adolescent patient with hydrocephalus, as a consequence of meningitis in the childhood, and chronic use of atrialventricular shunts. She presented fever and child for a long time, these symptoms were secondary to infection of the device, and shunt nephritis was also present.

Key words: Shunt nephritis, immune complexes, and atrial ventricular shunt infection.

\section{Introducción}

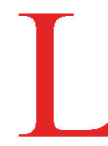

a nefritis por shunt es una complicación muy poco frecuente en los pacientes que presentan eccion de la derivación ventriculoatrial insertada por hidrocefalia congénita o adquirida. Esta fue descrita por Black en $1965^{1}$, época en la cual se descubrieron $148 \operatorname{casos}^{2,3}$, sin embargo, esta condición ha declinado llegando a ser una presentación muy inusual en los pacientes en las últimas décadas. La incidencia global de infección de la derivación está entre 3 y $11 \%$ y la nefritis por shunt se produce en cerca del $0,7-2,25 \%$ de los pacientes con una derivación infectada ${ }^{4}$.

Las bacterias implicadas, usualmente, son de baja virulencia y producen una infección crónica y larvada, permitiendo la formación de inmunocomplejos circulantes que producen depósitos subepiteliales y

Recibido:28 de enero de 2014 - Aceptado: 2 de mayo de 2014

Correspondencia: Viviana Parra, vivipaz16@hotmail.com 
en el mesangio. El pronóstico de esta enfermedad es bueno si se realiza un diagnóstico precoz, administrando un adecuado manejo antibiótico y realizando el retiro del dispositivo.

\section{Descripción del caso}

Paciente femenina de 16 años de edad, con antecedente de hidrocefalia secundaria a meningitis bacteriana en la infancia, que requirió derivación ventrículo-peritoneal a los 3 años de edad. Por múltiples complicaciones mecánicas se le cambó la derivación ventriculoatrial a los 14 años. Consulta por presentar pico febril aislado asociado a malestar general, náuseas y emesis; estos síntomas se correlacionan desde los 3 meses de la implantación de la derivación ventriculoatrial, presentando escalofríos matutinos diarios, malestar general y, en algunas ocasiones, diaforesis, sin documentar picos febriles, refiere orina oscura y fétida.

Al examen físico, alerta hidratada con FC: $145 \mathrm{x}$ min, FR 23 x min, TA: $110 / 75 \mathrm{mmhg}$, T $39.5^{\circ} \mathrm{c}$, SO2 $92 \%$, palidez mucocutánea generalizada, no signos de deshidratación, dispositivo de derivación palpable en región frontotemporal y cervical derecha, no doloroso a la palpación, sin signos de infección, ruidos cardiacos rítmicos, no soplos, ruidos respiratorios conservados sin agregados, abdomen sin masas palpables, no doloroso, edema grado II de miembros inferiores, hemianopsia bitemporal secundaria a meningitis en la infancia, no déficit motor ni sensitivo.

Se realizan paraclínicos al ingreso a urgencias evidenciando leucocitosis y neutrofilia sin presencia de formas inmaduras, aumento de PCR, procalcitonina negativa, anemia normocítica normocrómica, parcial de orina con hematuria y proteinuria en muestra aislada, no sugestivo de infección. Electrolitos dentro de límites normales, 4 hemocultivos positivos para cocos Gram positivos de lento crecimiento, tipo Micrococcus spp, por lo que se inicia manejo antimicrobiano con vancomicina el día 5 de hospitalización, la función renal fue normal. Ecocardiograma transesofágico sin evidencia de focos infecciosos en las estructuras cardiacas, válvula aórtica trivalva con insuficiencia de grado leve, función sistodiastólica normal, catéter de derivación ventriculoatrial en aurícula derecha sin alteración; Rx de tórax que evidencia catéter de derivación ventriculoatrial en adecuada posición (Figura 1). Ecografía de abdomen que solo evidencia esplenomegalia leve. Se realiza punción lumbar después de 4 días de antibiótico evidenciando presión de apertura $16 \mathrm{~cm} \mathrm{H2O}$, líquido cefalorraquídeo que evidencia hipoglucorraquia e hiperproteinorraquia, Gram, coloración de Ziehl-Neelsen, tinta china y cultivo negativo (Tabla 1). Dada la persistencia de hematuria y proteinuria en el uroanálisis se solicitan estudios complementarios, ecografía renal y de vías urinarias dentro de límites normales y complemento c3 y c4 los cuales estaban consumidos por lo que el servicio de nefrología considera que la paciente cursa con nefritis del shunt. El servicio de infectología considera continuar con vancomicina y plantean la necesidad del retiro del dispositivo de derivación.

\section{Discusión}

La nefritis por shunt es una glomerulonefritis mediada por inmunocomplejos, asociada con infección crónica del shunt ventriculoatrial. La incidencia puede llegar hasta $2,25 \%{ }^{4}$ en los pacientes portadores de derivaciones ventriculoatriales infectadas, afectando, principalmente, a los pacientes en edad pediátrica y adolescentes.

Esta complicación es excepcional en pacientes que son portadores de derivaciones ventriculoperitoneales, dado que se sugiere que el peritoneo actúa como una barrera bacteriana evitando de esta manera la formación de inmunocomplejos ${ }^{5}$. El tiempo de evolución en el cual se desarrolla esta condición desde la colocación del shunt y la presentación de la nefritis es muy variable, puede ir desde 3 semanas a 14 años, con una media en 4,4 años. En el caso de esta paciente transcurrieron un año y medio desde la colocación de la derivación.

El germen más común causante de la infección es el $S$. epidermidis, seguido por el $S$. aureus, sin embargo, también se han descrito casos con aislamiento de bacilos Gram negativos, anaerobios e incluso hongos $^{6}$. Los pacientes con derivaciones ventriculoauriculares infectadas presentan hemocultivos positivos en el $90 \%$ de los casos, esto contrasta con las 


\section{Figura 1.}

Rx de tórax que evidencia catéter de derivación ventriculoatrial en adecuada posición.
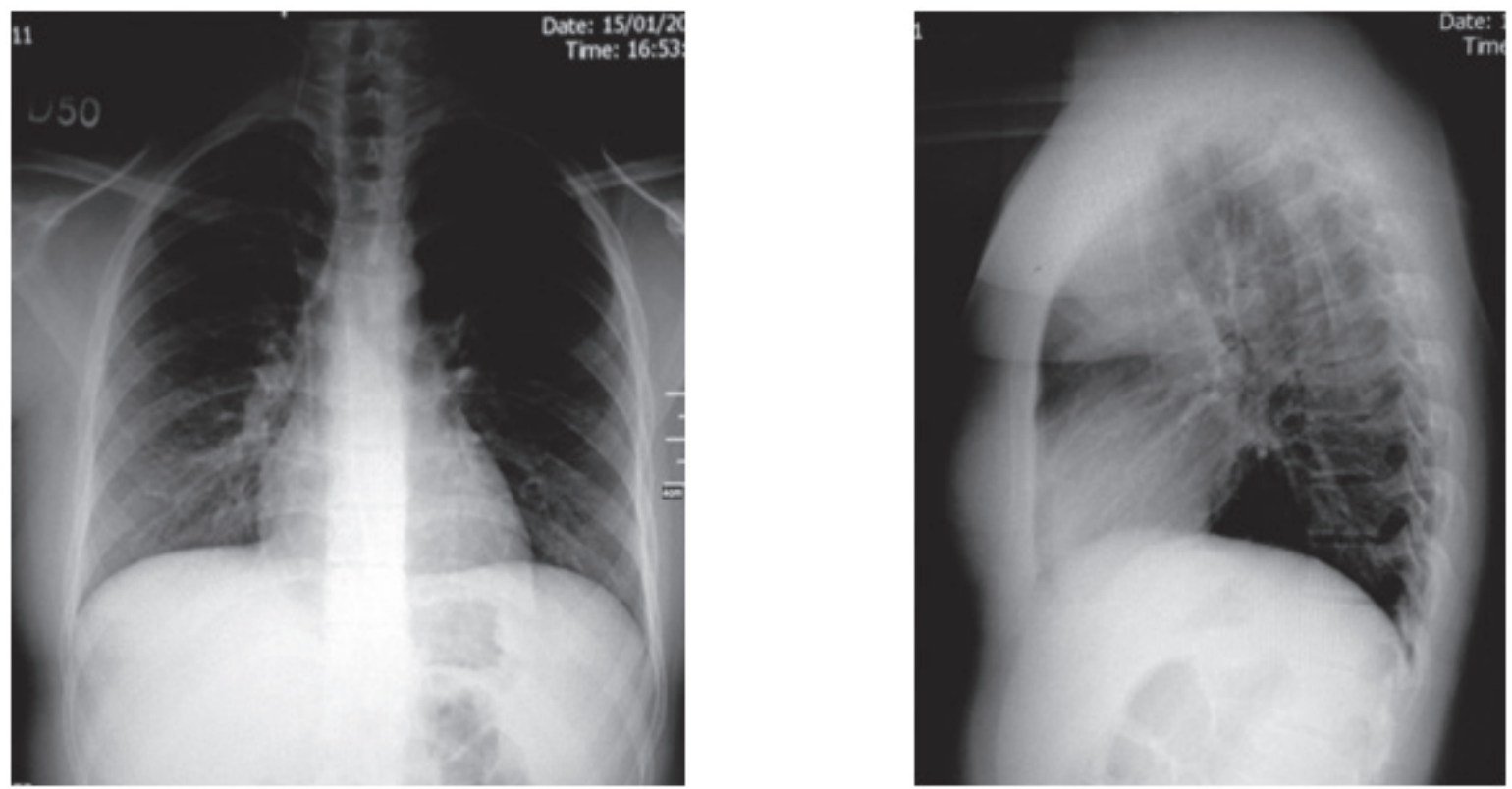

Tabla 1

Paraclínicos relevantes durante la hospitalización

\begin{tabular}{|c|c|c|c|c|c|}
\hline \multicolumn{2}{|c|}{ Hemograma } & \multicolumn{2}{|c|}{ LCR } & \multicolumn{2}{|c|}{ Química sanguínea } \\
\hline Leucocitos & 14.500 & Glucosa & $36 \mathrm{mg} / \mathrm{dl}$ & Glicemia & $85 \mathrm{mg} / \mathrm{dl}$ \\
\hline Neutrófilos & $85.2 \%$ & Proteínas & 84 & Nitrógeno ureico & 16 \\
\hline Hemoglobina & $10.6 \mathrm{mg} / \mathrm{dl}$ & \multirow[t]{4}{*}{ Citoquímico } & \multirow{4}{*}{$\begin{array}{l}\text { Xantocrómico, } \\
\text { límpido, leu: } \\
4 \mathrm{~mm} 3 \text {, hematíes } \\
15 \mathrm{~mm} 3,70 \% \\
\text { frescos }\end{array}$} & Creatinina & 0,6 \\
\hline Hematocrito & 32.2 & & & \multicolumn{2}{|c|}{ Complemento } \\
\hline Plaquetas & 211.000 & & & $\mathrm{C} 3$ & 55.20 \\
\hline Crioglobulinas & $1 / 8$ & & & $\mathrm{C} 4$ & 7.000 \\
\hline
\end{tabular}

infecciones de otros tipos de derivaciones de LCR, en las que la incidencia de hemocultivos negativos se aproxima al $80 \%$. El cuadro clínico se caracteriza por fiebre, hepatoesplenomegalia, anemia y púrpu$\mathrm{ra}^{7}$. Dentro de las manifestaciones renales se presenta hematuria macro y microscópica, con proteinuria de grado variable ${ }^{6}$ que incluso puede llegar a alcan- zar rangos nefróticos, los pacientes pueden presentar aumento de azoados, sin embargo, es inusual que al inicio del diagnóstico presenten injuria renal avanzada o cifras tensionales elevadas.

Dentro de los estudios que se solicitan está el complemento, dado que este tipo de nefritis se caracteriza por cursar con hipocomplementemia, con 
presencia de inmunocomplejos circulantes y crioglobulinas positivas como lo muestra esta paciente. Ocasionalmente también puede verse la positivización del factor reumatoide. Los paraclínicos, usualmente, retornan a la normalidad cuando se resuelve el proceso infeccioso. Es de resaltar que la nefritis del shunt puede ser la manifestación más temprana de la infección del catéter y la sintomatología que la precede a veces es muy bizarra.

La bacteriemia persistente por parte de gérmenes de baja virulencia que se produce en esta patología trae como consecuencia la aparición de inmunocomplejos circulantes, los cuales saturan el sistema reticuloendotelial y se depositan en los capilares glomerulares, produciendo activación de la cascada del complemento y reacción inflamatoria crónica la cual lleva a lesión renal ${ }^{6-8}$.

Los hallazgos histológicos en las biopsias renales evidencian lesiones proliferativas tipo glomerulonefritis mesangiocapilar, proliferación endocapilar difusa y glomerulonefritis mensangial. La microscopia electrónica demuestra depósitos electrodensos con patrón granular a nivel del mesangio y del espacio subendotelial. En la inmunofluorescencia se evidencian inmunoglobulinas tipo IgM en el $84 \%$ e IgG en el 66\%, complemento C3 94\% y antígenos bacterianos $^{6}$. A nuestra paciente no se le realizó la biopsia por presentar todos los criterios diagnósticos.

El tratamiento de la nefritis del shunt se basa en la erradicación de la infección y en el recambio valvular, el antibiótico se recomienda de manera sistémica $\mathrm{y}$, en algunos casos, puede combinarse con antibiótico intratecal. En cuanto al recambio valvular se recomienda colocar una nueva derivación en un lugar diferente a la previamente colocada ${ }^{9-10}$. Algunos autores recomiendan solo el manejo con antibiótico interventricular, sin embargo, las tasas de curación son solo cercanas al $50 \%$.

Por todo lo anterior, aunque esta condición sea inusual hay que sospecharla y tener en cuenta que el diagnóstico clínico de las infecciones crónicas del shunt ventriculoatrial no es fácil y los cultivos de sangre y líquido cefalorraquídeo pueden ser negativos. Por ello, esta entidad es a menudo subdiagnosticada y el tratamiento se difiere meses o años; la clave en la resolución de los síntomas y la disminución del riesgo de daño renal está en realizar un diagnóstico precoz y un adecuado manejo terapéutico ${ }^{11}$.

\section{Conflicto de interés}

Los autores declaran no tener ningún conflicto de interés.

\section{Referencias bibliográficas}

1. Black J, Chaacombe D, Ockenden B. Nephrotic syndrome associated with bacteremia after shunt operations for hydrocephalus, Lancet, 1965;2:921-924.

2. Wyatt R, Walsh J, Holland N. Shunt nephritis it's role of the complement system in its pathogenesis and management. J Neurosurg, 1981;55:99-107.

3. Bogdanovic R, Marjanovic B, Nikolic V. Shunt nephritis associated with Moraxella Bovis. ActaPaediatr, 1996;85:882883.

4. Haffner D, Schindera F, Aschoff A, Matthias S, Waldhere R, Scharer K. The clinical spectrum of shunt nephritis. Nephrol Dial Transplant, 1997;12:1143-8.

5. Narchi H, Taylor R, Azmy A, Murphy A. Shunt nephritis. J PediatrSurg, 1988, 23:839-841

6. Haffner, D; Schindera, F; Aschoff A; Matthias S; Waldherr, R; Schärer, K. The clinical spectrum of shunt nephritis. Nephrol Dial Transplant. 1997;12:1143-1148.

7. $\quad$ Searle M, Lee H. Ventriculo-atrial shuntnephritis. Postgraduate Medical Journal, 1982;58:566-569 
8. Groeneveld A, Nommensen F, Mulink H, Ooms E. Shunt nephritis associated with Propionobacterium acnes with demostration of the antigen in the glomeruli. Nephron, 1982;32:365-369.

9. Rifkinson M, Rifkinson N, Leong T. Shunt nephritis case report. J Neurosurg, 1991;74:656-659.

10. Blount J, Campell J, Haines S. Complications in ventricular cerebrospinal fluid shunting. NeurosurgClin North Am, 1993;4:633-656.

11. Conde F. Roldán H. Prat R. Galeano L. Lourido J. Febles P. González-Feria L. Nefritis por shunt. Neurocirugía. 2001;12:270. 